material for a sacrificial meal. One of the most noteworthy finds was a gold torque, in form similar to the torque found at Troy and presumably of Irish origin. Lectures on the work of the season are being given at University College, London, on May 19 at 2.30 P.M. and May 21 at 3 P.M., entrance free, without ticket; and the usual exhibition will be open at the College on July 11-Aug. 6.

\section{Animals and Electric Shocks}

Ir is well known to electricians that animals are much more sensitive to electric shock than human beings. Quite low voltages, of the order of 20 volts, are dangerous to cattle and horses. About twenty years ago, when rural electrification began to increase on the Continent, fatalities to these animals began to occur, and it was found necessary to devise methods for mitigating the danger. As the electrification of farms has now been begun in Great Britain, the paper by $\mathbf{T}$. C. Gilbert in the Electrician for April 29, in which he discusses some of the effective safety devices used abroad, should prove useful. Wiring systems where the 'live' wires are surrounded by metal which is connected to 'earth' are perhaps the safest, at least in towns, where the mains of the water supply system, into which any leakage currents usually flow, form an excellent earth. In rural districts, earths are made by burying metal plates or pipes. In this case the resistance of the earth may be of the order of $50 \mathrm{ohms}$, and so even if a leakage current be less than an ampere, the difference of potential of the ground near where the pipe is inserted and four feet away may cause a dangerous shock to a large animal standing with a foreleg near the pipe and a hindleg four feet from it. Mr. Gilbert records a very exceptional case where no less than six cows in one farm were killed from this cause. So far as we know, no fatalities to human beings have ever occurred in this way. We have heard of cases where mild shocks have been felt in the street, when a pedestrian steps from one part of the pavement to the other, due to a fault in an underground main. The effective methods used abroad show that the risks to cattle can be made almost negligible.

Spore Dissemination through the Upper Atmosphere

DURING the War, aeroplanes came to be used to an increasing extent for the direct investigation of meteorological conditions in the upper atmosphere. We learn from an article that forms one of the "Why the Weather" series, by C. F. Talman, issued by Science Service, Washington, D.C., that the aeroplane is being used in analogous biological investigations by the U.S. Bureau of Plant Industry to determine, among other matters, the height to which the spores of the dreaded black stem rust occur in the American spring wheat area. The spores are collected on glass microscope slides covered with a very thin coating of vaseline. It has been found that they extend up to a height of about $10,000 \mathrm{ft}$. above the earth. From the results of other investigators on the rate of fall in still air of the spores of white-pine blister rust, a spore only slightly smaller than the black stem rust spore, it may be concluded that the black rust spores would occupy about two days in falling from $10,000 \mathrm{ft}$. to the ground, in the absence of any net upward or downward component of the wind. Since it is no rare event for the wind above the first few hundred feet to travel a thousand miles or more in a day, it is evident that regions lying far to leeward of infected areas may receive spores from these great altitudes.

\section{Cave Exploration in Western China}

THE United States National Museum has received a large collection of objects which have been obtained from the caves of Szechwan, Western China, by Mr. David C. Graham, of the Smithsonian Institution, Washington, D.C. This explorer has found that a large number of the innumerable caves of Szechwan and the Tibetan border were used as tombs by the Chinese at about the beginning of the Christian era; but no evidence is forthcoming to support the view that they were once inhabited by aborigines who preceded the coming of the Chinese. The caves are generally found in steep places, both singly and in groups. They are difficult of access, and vary in depth from a few feet to 130 feet, being about six feet wide and six feet high. Some show signs of chisel marks. Nearly all the caves have coffin niches, the coffins being of earthenware. Some coffins, however, are merely cavities chiselled in the stone and fitted with stone lids. Among the funerary offerings, the large number of figurines of human form is noteworthy. Some of these in costume and general appearance present a remarkable similarity to the people of to-day.

\section{Norman Lockyer Observatory}

Sir Frank Dyson, Astronomer Royal, will open the new Mond photographic equatorial and dome at the Norman Lockyer Observatory, Salcombe Regis, Sidmouth, on May 28. The Norman Lockyer Observatory is the only astronomical observatory in Great Britain founded and maintained by a private corporation under the Companies (Consolidation) Act of 1908. Since it was started, nearly twenty years ago, it has been equipped and maintained entirely by private donations. The equipment includes two twin telescopes, one with a 10 in. object glass and a 12 in. prismatic camera, and the other with a $10 \mathrm{in.} \mathrm{object}$ glass and a 9 in. prismatic camera for photographing the spectra of stars and other celestial bodies. A very large collection of such photographs, numbering 6500 , has already been taken at the Observatory, affording valuable records of the nature and movements of objects in the stellar universe. Dr. Robert Mond, who has been a generous supporter of the Observatory since it was founded, has now presented a unique photographic equatorial, with a separate building and dome to house it. The instrument consists of a battery of four cameras with clock mechanism, so that it will be possible to follow automatically movements of the heavens over a wide field of the sky.

\section{Expeditions of the Soviet Academy of Science}

Tris year the Soviet Academy of Science is sending out ninety-nine scientific expeditions to explore

$$
\text { No. 3264, VoL. 129] }
$$

